\title{
A Study on Comprehensive Evaluation of the Water- saving Irrigation in Arid Area of Northeast China
}

\author{
Xiaoyan Han \\ College of Economy and Management \\ Shenyang Agricultural University \\ Shenyang, China
}

\author{
Xue Jin \\ College of Economy and Management \\ Shenyang Agricultural University \\ Shenyang, China
}

\begin{abstract}
Water saving irrigation is the key technology and strategy to improve the agricultural development in the arid area of north China. Since 2012 the government paid enormous subsidies to invest the water infrastructure in northeast china. The aim of this paper is to estimate the comprehensive effect of the water saving irrigation and provide the practical evidence for the subside policy evaluation. The study is based on the field scale data collected from 192 maize households in Tongliao city of the Nei Monggol Autonomous Region where is the typical irrigating agriculture area. The paper established an index system to evaluate the economic benefits, social benefits and ecological benefits of water saving irrigation technology. In order to consistent with the previous research, the criteria is made into excellent, good and bad. The results show that economic benefits and social benefits are good. However, the ecological benefits is bad because of the soil pollution brought by the plastic film. So to further improve the technology level still is the focus of the China water-saving agricultural development. And the government should pay more attention on the constraints of farmer technology adoption and the core problem such as the film residual and the ancillary facility should be solved effectively.
\end{abstract}

Keywords-water saving irrigation; the comprehensive evaluation; the index system

\section{INTRODUCTION}

Irrigation in many countries is an old art-as old as civilization-but for the whole world it is a modern science-the science of survival and development. Especially for the arid regions irrigation is of the first importance because the available water supply is limited. In these cases, irrigation must decide between fully irrigating the field for maximum production and reducing the water consumption. So the development of water saving irrigation technology has been greatly advanced.

In addition to rational water use and irrigation extension, there is a need for evaluating the effect of irrigation technology Jeffy. R. Williams et al.(1988) formulated the ICEASE model (irrigation cost estimator and system evaluator) for obtaining the irrigation cost and irrigation benefits under different operating condition of diversified water-saving irrigation system. Charles et al.(1988)have developed a program in their book evaluation method of irrigation system. The program establishes the indexes system consisted of technical and

The paper is supported by the national science foundation project of no.71303160. synthetic indicators which based on the data obtained from the comprehensive survey of irrigation district. Manuel Martin Rodriguez et al. (2002) have put forward a method for technical and economical evaluation on area of water saving agriculture. Based on the analysis of two type farm households be located the same nature conditions in dry farming areas, who using of water saving irrigation and the ones without using, the method established an economic benefit evaluation model of water saving agriculture. Li Xiaoyuan (2010) have developed a combined weighting method to estimate the index weigh. Wu Jingshe et al. (2004) formulated a multi-rounds expert consultation method to make the index system and combined both expert consultation and AHP to calculate the weight and accomplish the technology evaluation. Zhu Zhonglin et al. (2007) used the fuzzy hierarchy comprehensive evaluation for estimating the effect of water saving irrigation in Sichuan. And Li Ping et al. (2012) used the fuzzy comprehensive evaluation model and multi-indexes method for estimating the development level of water saving irrigation in Henan province.

The purpose of this paper is to estimate the comprehensive effect of water saving irrigation in arid region of northeast China. An index system has been established by considering economic benefits, social benefits and ecology benefits. The study is based on the primary data collected from 192 sample farms spread five villages in Tongliao city of the inner Monggol Autonomous Region, where spring maize is the main crop. The villages were selected with the typical sampling and the farms were selected with random sampling.

\section{The Study Site AND THE DESCRIPTION OF THE FINDINGS}

In the Inner Monggol, the maize total yield surpasses 2 million tonne annually and more than half are product in Tongliao city. But Tongliao city is one of the most water shortage cities in China. Droughts occur frequently in this region and the fact of facing a serious water shortage is the most serious limiting factor of agricultural development. In Tongliao city the per capita share of water resources is less than 1200 cubic meters and the number is lower 1000 cubic meters than the national average level. The level of the cultivated land occupying the water resources is less than 400 cubic meters per ha. At the same time, the field irrigation annually account for $85 \%$ of the whole municipal gross used 
water and this number is higher about twenty points than the national average. Moreover the $95.46 \%$ of the water consume of the city comes from the groundwater. This results in that to development water saving irrigation project has particular important value for improving the agricultural production conditions and the water resources protection.

Since 2011 the government had carried out the watersaving irrigation projects in the region. According to the requirements of the project and agriculture development, the resources saving principle and output increasing principle have been considered for the study.

In the construction of the water saving irrigation project, 30000 motor-pumped well have been completed and has been put into use. The typical technologies of the water-saving project are the drip irrigation with film and the low pressure tube filling. The farmers survey found that there is far differences existing between the farmer's irrigation behaviors. The following table reports the general situation of watersaving irrigation production.

TABLE I. THE DESCRIPTIVE STATISTICAL ANALYSIS OF FARM IRRIGATION

\begin{tabular}{|l|l|l|l|l|}
\hline \multicolumn{1}{|c|}{ variable } & $\begin{array}{c}\text { Minim } \\
\text { um }\end{array}$ & $\begin{array}{c}\text { maxim } \\
\text { um }\end{array}$ & \multicolumn{1}{|c|}{ mean } & $\begin{array}{c}\text { Standard } \\
\text { deviation }\end{array}$ \\
\hline $\begin{array}{l}\text { frequency of } \\
\text { irrigation }\end{array}$ & 1 & 7 & 3.67 & 1.40 \\
\hline $\begin{array}{l}\text { irrigation volume } \\
\text { every time } \\
\text { (m3/ha) }\end{array}$ & 120 & 2430 & 960 & 553.05 \\
\hline $\begin{array}{l}\text { irrigation volume } \\
\text { each season } \\
\text { (m3/ha) }\end{array}$ & 982.95 & 6880.65 & 3605.85 & 1380.6 \\
\hline $\begin{array}{l}\text { rrigation costs } \\
\text { each season } \\
\text { (yuan/ha) }\end{array}$ & 90 & 1875 & 660.3 & 414.75 \\
\hline
\end{tabular}

The area has a high potential for maize production. But farm production has been impacted by a variety of factors. Be Consistent with this, farmers made various responses in the questionnaire survey. Only six samples considered that the water saving irrigation significantly promoted the increase of their income, taking 3 percent in the total samples. At the same time, 16 percent, 37 percent and 44 percent of the total samples respectively think the water saving irrigation has relatively significantly influences, general influences and non-significant influences on the increase of farm income.

As for whether the extension of water saving irrigation has significantly influences on farmer's attitude to agricultural technology, the answer of significantly, relatively significantly, general and non-significant influences respectively take 12 percent, 34 percent, 42 percent and 12 percent of the total sample.

The response on what extent the water saving irrigation technology changing the soil and water conditions of the farmland, with foregoing partition criterion, respectively takes 16 percent, 32 percent, 45 percent and 7 percent of the total sample.
The ecological benefit of water-saving agriculture is mainly on the protection of the ecological environment. But the survey found that $73 \%$ of farmers think it's difficult to residue the plastic film clearly. So the plastic film is the core problem needed to solve in extending the water-saving irrigation technology. $26.5 \%$ and $34 \%$ of the farmers respectively think the water saving irrigation have significant influence and relative significant influences on the soil moisture, however $37 \%$ farmers indicates there is a general impact and 3\% farmers indicates there is non-significant impact.

\section{THE ESTABLISHMENT OF THE INDEX SYSTEM}

The study established an index system for processing the comprehensive evaluation on the water-saving irrigation. The index system consists of three levels indicators and the secondary indicators separately evaluate the economic benefits, social benefits and ecological benefits. Every secondary indicators measured by three questions as shown in the table.

The economic benefits of the Water-saving irrigation technology are mainly reflected in the yield. So the three-grade indicators measuring the economic benefits are based on the compare the farm using the technology and the ones without using. The economic benefit increment per unit area is defined as the difference of the net earning per unit area between the two kinds farms. The yield increment per unit area is defined as the yield gap between the water saving irrigation farm and the common irrigation farm. The increment of rate of output/input is calculated by the rate of output/input of the water saving irrigation farm minus that of the common irrigation farm.

The three-grade indicators measuring the social benefits and ecology benefits all are qualitative indexes which reflected by the degree of the cognition and satisfaction on the water saving irrigation technology. And the parameter values were gained by the questionnaire survey.

\section{TABLE II. THE INDEX SYSTEM OF THE COMPREHENSIVE EVALUATION} ON THE WATER-SAVING IRRIGATION

\begin{tabular}{|c|c|c|}
\hline $\begin{array}{l}\text { first grade } \\
\text { index a }\end{array}$ & $\begin{array}{l}\text { second } \\
\text { index } b\end{array}$ & three-grade index $\mathrm{c}$ \\
\hline \multirow{9}{*}{$\begin{array}{l}\text { the } \\
\text { comprehensive } \\
\text { benefits }\end{array}$} & \multirow{3}{*}{$\begin{array}{l}\text { economic } \\
\text { benefits b1 }\end{array}$} & Economic benefit increment per unit area $\mathrm{c} 1$ \\
\hline & & yield increment per unit area $\quad$ c2 \\
\hline & & the increment of rate of output/input $\mathrm{c} 3$ \\
\hline & \multirow{3}{*}{$\begin{array}{l}\text { social } \\
\text { benefits b2 }\end{array}$} & $\begin{array}{l}\text { The significant level on which water saving irrigation } \\
\text { increasing the farm income c4 }\end{array}$ \\
\hline & & $\begin{array}{l}\text { The degree on which the extend of water saving } \\
\text { irrigation influencing the farmer's technology } \\
\text { attitude c5 }\end{array}$ \\
\hline & & $\begin{array}{l}\text { The improvement degree of production conditions in } \\
\text { the farmland brought by water saving irrigation c6 }\end{array}$ \\
\hline & \multirow{3}{*}{$\begin{array}{l}\text { ecological } \\
\text { benefits b3 }\end{array}$} & $\begin{array}{l}\text { The improvement degree of soil and water conditions } \\
\text { in the farmland brought by water saving irrigation } \\
\text { c7 }\end{array}$ \\
\hline & & the soil pollution caused by the plastic film $\mathrm{c} 8$ \\
\hline & & the water pollution caused by the plastic film c9 \\
\hline
\end{tabular}




\section{THE PARAMETER DETERMINATION}

The study defines the parameter $\mathrm{R}$ as the score of the comprehensive evaluation on the water saving irrigation technology. In the other word, $\mathrm{R}$ is the score of indicator a and it' $s$ the final evaluation numerical value of the technology. Based on the number of $\mathrm{R}$, the study make the evaluation results. The formula for $\mathrm{R}$ is:

$$
R=\sum_{i=1}^{9} Y_{i} q_{i}=q_{1} Y_{1}+q_{2} Y_{2}+q_{3} Y_{3}+q_{4} Y_{4}+q_{5} Y_{5}+q_{6} Y_{6}+q_{7} Y_{7}+q_{8} Y_{8}+q_{9} Y_{9}
$$

In the formula, $Y_{i}$ is the indicator's ideal value or actual value and $q_{i}$ is the indicator's weight. $i$ represent nine indicators in the index system, $i=1,2, \ldots \ldots .9$

The score of $q_{i}$ is determined by the Delphi method and the analysis of comparing the references. Combining the two results, the weight assignment of two-grade indicators is 0.33 respectively. The weight assignment of three-grade indicators is 0.11 respectively. In the process of determining weights experts agree that it is equally important for the yield increase, the income growth and the conditions improvement such as soil moisture, water resources protection, wind erosion and so on. And the assignment also accords with the actual situation of the study sit.

To calculate the value of the index the study uses the analytic hierarchy process. The score of the indicators is obtained by the weighted average of the next grade index. So the determination of the weight and to calculate the score of each index are the core step of the evaluation research. The study uses the following steps:

The first step is to estimate the reference value of the threegrade indicators. According to the answer of the farm questionnaire investigates, the Likert scale and weighted average method were used to gain the reference value of each indicator ( 1 to $\mathrm{c} 9)$.

The second step is to revised the reference values to the actual values. The step uses the Delphi method. The expert group is consists of the agricultural economics researchers, the technologist, the local technicians and the farmer representative who using the water saving technology.

The third step is to estimate the index's ideal value. The ideal value of the index is the correlation standard to make the judgment. In order to establish the standard for evaluation and make the judgment results objectively, the ideal value of the index system has been assigned by the Delphi method and the analysis of comparing the references. So to carry out a comparative study with the precious research, the study uses the similar measurement scale. All the actual values and the ideal values of the indexes are reported in the table two.

\section{THE RESUlTS}

The evaluation score for each index was determined both by laying calculation and weight average.
For example, to get the actual value and the ideal value of secondary index, the actual and the ideal estimated score of the three-grade indicators were put into the formula respectively. the calculation of the economic benefit index is as follows:

$$
\begin{aligned}
& R_{\text {ideal }}=\sum_{i=1}^{3} Y_{i} q_{i}=7 * 0.11+8 * 0.11+6 * 0.11=2.31 \\
& R_{\text {actual }}=\sum_{i=1}^{3} Y_{i} q_{i}=5 * 0.11+5 * 0.11+4 * 0.11=1.54
\end{aligned}
$$

\begin{tabular}{|c|c|c|c|c|c|c|c|c|}
\hline variab & & $\begin{array}{l}\text { Ideal } \\
\text { value }\end{array}$ & $\begin{array}{c}\text { Actual } \\
\text { value }\end{array}$ & weight & $\begin{array}{c}\text { Actual } \\
\text { score }\end{array}$ & \begin{tabular}{|l} 
Ideal \\
score
\end{tabular} & $\begin{array}{l}\text { The } \\
\text { ratio }\end{array}$ & $\begin{array}{c}\text { Judging } \\
\text { results }\end{array}$ \\
\hline \multirow{3}{*}{$\begin{array}{l}\text { economic } \\
\text { benefits } \\
\text { b1 }\end{array}$} & C1 & 7 & 5 & 0.11 & \multirow{3}{*}{1.54} & \multirow{3}{*}{2.31} & \multirow{3}{*}{0.67} & \multirow{3}{*}{ good } \\
\hline & C2 & 8 & 5 & 0.11 & & & & \\
\hline & C3 & 6 & 4 & 0.11 & & & & \\
\hline \multirow{3}{*}{$\begin{array}{l}\text { social } \\
\text { benefits } \\
\text { b2 }\end{array}$} & $\mathrm{C} 4$ & 6 & 4 & 0.11 & \multirow{3}{*}{1.65} & \multirow{3}{*}{2.09} & \multirow{3}{*}{0.79} & \multirow{3}{*}{ good } \\
\hline & C5 & 6 & 5 & 0.11 & & & & \\
\hline & C6 & 7 & 6 & 0.11 & & & & \\
\hline \multirow{3}{*}{$\begin{array}{l}\text { ecological } \\
\text { benefits } \\
\text { b3 }\end{array}$} & C7 & 7 & 6 & 0.11 & \multirow{3}{*}{1.1} & \multirow{3}{*}{1.65} & \multirow{3}{*}{0.67} & \multirow{3}{*}{ bed } \\
\hline & C8 & 4 & 2 & 0.11 & & & & \\
\hline & C9 & 4 & 2 & 0.11 & & & & \\
\hline
\end{tabular}$$
R_{\text {ratio }}=R_{\text {actual }} / R_{\text {ideal }}=0.67
$$

TABLE III. The StATISTIC TABLE OF THE INDEX JUdGING RESUlT

Note : The judging results were referred to the literature Lv Chaoyang et al.(2008)

The standard to make the judgment is the ratio of the actual value to the ideal value. Referencing precious literature, the following criteria were used:

When the ratio of economic benefits is equal or more then 0.8 , the technology effect to be judged as excellent; When the ratio of economic benefits is between 0.6 and 0.8 , the technology effect to be judged as good and it's bed if the ratio is less than 0.6. When the ratio of social benefits is equal or more then 0.8 , the technology effect to be judged as excellent; When the ratio of social benefit is between 0.65 and 0.8 , the technology effect to be judged as good and the judgment is bed if the ratio is less than 0.65 . When the ratio of the ecology benefit is equal or more then 0.85 , the technology effect to be judged as excellent; When the ratio is between 0.7 and 0.85 , the technology effect to be judged as good and the judgment is bed if the ratio is less than 0.7 .

Comparing the criteria and the estimation ratio of benefits index, the study made the judgment. And the results showed that the water saving irrigation technology brought both good economic and social benefits and bed ecology effect. This conclusion is consistent with the situation reflected by the farmers in the survey. 


\section{CONCLUSION AND SUGGESTION}

The study makes a statistical analysis on the investigation findings of the effect of the water saving irrigation. Results are as followings: the yield gap between the farm using water saving irrigation and the ones without using is $143.4 \mathrm{~kg} / \mathrm{ha}$, which pushes the total revenue increasing about 80yuan/ha. On the average level, the farm adopting the water saving irrigation technology can get an income of 8141.25yuan/ha. Considering the effect in cost saving, the water saving irrigation farm get an excess about 1787.75yuan/ha than that of the farm without adopting the technology. This is the main reasons that the economics benefit and the social benefit can be rated as good.

By contrast, the fact that the water saving irrigation agriculture needs large quantities of the plastic film has been lead to the difficulty in getting rid of the residual film. And because of the shortage of applicable film-weeding machine, the farmers must put more labor and capital in the soil preparation. Therefore, there are empirical evidences that the ecology benefit index of the water saving irrigation has been judged as bed.

The other problem in the water saving irrigation agriculture is the matching of the cultivation technology and irrigation technology. Because the local agriculture production depends on the irrigation, the farm had formed the habit of increasing irrigation water. So the data conclusion on the technical water saving effect is not significant as well as the expected. And the impact from the cultivation technology is mixed with the irrigation effect. All the factors together make a complex influence on the evaluation conclusion.

The study confirmed that the extension of the water saving irrigation had achieved the primary aims of increasing the yield, the farm income growth and the appropriate use of water resources. Moreover, the strategies of the water saving agriculture development should be strengthened in the integrity of the technology and there should be a well linkage between farmers and the researchers and the extensionists.

It had been emphasized that agricultural technique service system should be improved and good technology effect due to the correct and properly technology adoption. Though, there is a long way from the supporting measure and infrastructure to the requirement of the development. Therefore the government should pay more attention on the constraints of farmer technology adoption. And the core problem such as the film residual and the ancillary facility should be solved effectively.

With the analysis of the survey data, it can be concluded that the macro effect of the water saving irrigation is better than its performance in the micro household level. Therefore, in the future the extend of the water saving irrigation should be carry out among the advantages region and farms. And it is necessary to adjust and refine the support policies. Such institutions and supervision as water resources assessment and farmland ecological assessment should be built up as soon as possible.

\section{REFERENCES}

[1] G. Eason, B. Noble, and I.N. Sneddon, "On certain integrals of Jerry R Williams, Orlan Hbuller, Gary Jdvorak.1988. A microcomputer model for irrigation system evaluation .Southern Journal of Agricultural Economics. 20: 145- 151.

[2] Charlesm Burt, Robert Ewalker, Stuartw Styles.1988.Irrigation system evaluation manual .California Dept of Water Resource and Dept of Agriculture Eng.

[3] Manuel Mart in Rodriguez.2002. Evaluation of irrigation projects and water resource management a method- -logical proposal Sustainable Development.10: 90- 102.

[4] Li Xiaoyuan, Zhu Meiling, He Jiwu. 2010. Agricultural efficient watersaving irrigation technology evaluation index system of Economic Construction in Arid Area.Rural Economy and Science, 04: 62-63.

[5] Wu Jing she, Kang Shao zhong, Wan G Jing lei.2004.Study on Selection and Gradation of the Evaluation Index of Comprehensive Effects in the Water-saving Irrigation.Journal of Irrigation and Drainage, 05:17-19.

[6] Zhu Zhong lin, Chen Jiankang, Liu Xioajun, Li Yan ling, Xu Cheng.2007.The Assess Index System and Evaluation Model of WaterSaving Agricultural Benefits in Hilly Area, Si Chuan. Journal of Mountain Science, 04:483-489.

[7] Lu Zhao-yang, Guo Zong-lou,2008, Research on the Indexes System and theMethod for Total Benefit Evaluation of Water-saving Irrigation District, Water saving irrigation, 03:52-54.

[8] He Yanguo, Fu Qiang, Feng Yan, Zhao Xiaoyong, Li Lin.2006.The Grade of Comprehensive Benefit of Water-saving Agriculture in Semiarid and Anti drought Irrigating Region of Northeast China.Journal of Irrigation and Drainage,06:57-60+64 